\title{
ALOCAÇÃO DOS PRODUTOS NAS GÔNDOLAS DOS SUPERMERCADOS: UM ESTUDO DE CASO
}

\section{GESTÃO \\ $\&$ \\ PRODUÇÃO}

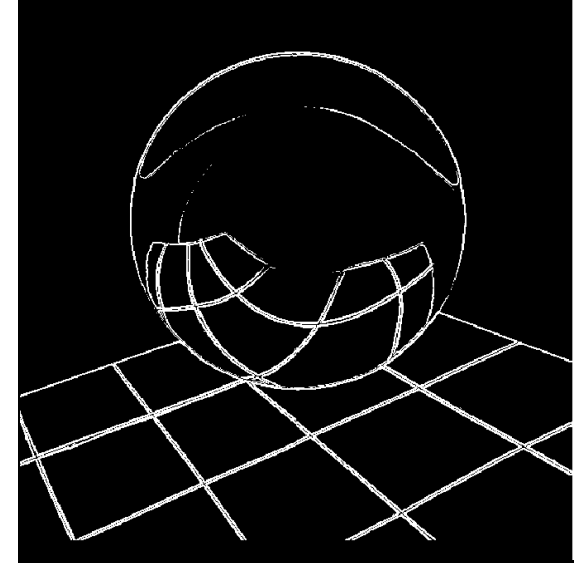

v.9, n.1, p.45-61, abr. 2002
Rodrigo Coltelli Cesarino José Vicente Caixeta Filho

Departamento de Economia, Administração e Sociologia

ESALQ - Universidade de São Paulo

Piracicaba - SP

\section{Resumo}

Este é um estudo feito com o objetivo de verificar a eventual existência de um padrão de distribuição dos produtos nas gôndolas dos supermercados, em função do tamanho e formato das lojas. Para tal, foi conduzido um estudo de caso, em lojas de uma rede de supermercados na cidade de São Paulo, onde foi avaliada a relação existente entre as decisões de alocação de espaço e o tamanho e formato das lojas. Estando correlacionados o espaço alocado para as seções e o tamanho das lojas, tem-se uma padronização maior para as lojas da rede. Ou, se não existir tal correlação, pode existir uma maior especificidade de atendimento da demanda local para cada loja. Foram considerados, neste estudo, os formatos compacto, convencional e grande para os supermercados. Quanto ao critério de classificação das seções das lojas da rede pesquisada, foi utilizada uma própria. Os resultados sugerem que as lojas de formato compacto e convencional sejam desenhadas para atender uma demanda ainda mais localizada que as lojas de formato grande. O fato de não se rejeitar sistematicamente a hipótese nula de que a correlação entre o tamanho da loja e o tamanho da seção seja zero, para todas as seções nos três formatos de loja, é um forte indicador de que as decisões gerenciais, no tocante à alocação de espaço nas gôndolas das lojas da rede pesquisada, sejam muito mais localizadas do que poderia se esperar em uma rede. Principalmente levando-se em conta que a rede pesquisada tem a maioria de seus produtos originados a partir de um centro de distribuição.

Palavras-chave: gôndolas, elasticidade-espaço, sortimento eficiente, supermercado. 


\section{Introdução}

$\mathrm{D}$ entre as decisões operacionais correntes na atividade varejista, são fundamentais as relacionadas ao lay-out interno do supermercado, mais especificamente à disposição dos produtos. Frente às limitações de espaço interno, o arranjo encontrado para a distribuição dos produtos não somente vai influenciar diretamente as vendas de cada loja, como também significa um componente importante da estrutura de custos do supermercado.

Por outro lado, é crescente a necessidade de personalização dos serviços do varejo, ou seja, o consumidor exige um sortimento adequado de produtos e um atendimento cada vez mais direto (TENDÊNCIAS de lay-out..., 1999).

O objetivo principal deste trabalho foi o desenvolvimento de um estudo exploratório visando verificar a eventual existência de um padrão de distribuição dos produtos nas gôndolas dos supermercados, em função do tamanho e formato das lojas. Para tal, foi conduzido um estudo de caso, em lojas de uma rede de supermercados na cidade de São Paulo, onde foi avaliada a relação existente entre as decisões de alocação de espaço e o tamanho e formato das lojas. Estando correlacionados o espaço alocado para as seções e o tamanho das lojas, teremos uma maior padronização para as lojas da rede. $\mathrm{Ou}$, se não existir tal correlação, pode existir uma maior especificidade de atendimento da demanda local para cada loja.

\section{O Conceito de Elasticidade-Espaço}

A o discutirem sobre a percepção visual do consumidor, PHILLIPS \& BRADSHAW (1993) apud DESMET \& RENAUDIN (1998) demonstram que produtos que ocupam maior espaço nas gôndolas possuem maior probabilidade de serem:

a) percebidos pelo consumidor;

b) analisados e/ou manuseados;

c) terem sua imagem gravada na mente do consumidor; e

d) efetivamente colocados nos carrinhos.
Esse fenômeno motivou a utilização do conceito de elasticidade-espaço nos estudos sobre alocação de produtos no varejo. Não só pela facilidade oferecida para a formulação de modelos matemáticos, como também por auxiliar a mensuração do fenômeno em si.

De acordo com YANG \& CHEN (1999), elasticidade-espaço é definida como sendo a razão entre a mudança relativa nas vendas por unidade modificada na alocação de espaço na gôndola. Ou, de acordo com CURHAN (1972, p. 406), "elasticidade-espaço é a razão entre a mudança relativa em unidades de venda, pela mudança relativa no espaço ocupado pelo produto na gôndola". Pode ser representada pela seguinte expressão:

$$
\varepsilon_{e}=\frac{\frac{\Delta s}{s}}{\frac{\Delta \lambda}{\lambda}}
$$

ou,

$$
\varepsilon_{e}=\frac{d s}{d \lambda} \frac{\lambda}{s}
$$

onde:

$\varepsilon=$ elasticidade-espaço;

$s=$ vendas, em unidades monetárias; e

$\lambda=$ espaço, em unidades de comprimento.

O espaço em questão deve ser entendido como a parte visível do produto, ou melhor, a parte do produto visível para o consumidor. Geralmente, será a parte frontal da gôndola, mas dependendo do posicionamento do produto na loja, podem existir mais faces visíveis para o consumidor. Um exemplo são as pilhas de produtos em pontos estratégicos da loja, que costumam ter três ou quatro faces visíveis, além de estarem em pontos de passagem. Elas terão três faces visíveis se uma delas estiver voltada para a lateral de uma gôndola, por exemplo.

A esse respeito, FRANK \& MASSY (1970) propuseram as seguintes questões em um estudo sobre a posição relativa dos produtos nas gôndolas: 
a) qual é o efeito de se variar o número de linhas (considerando-se as faces) de uma categoria de produtos na gôndola?

b) qual o efeito de se variar a altura (da linha) em relação à base da gôndola? e

c) existe interação entre o efeito das linhas das gôndolas e o nível onde elas se encontram?

Quanto aos resultados dessa pesquisa, os referidos autores encontraram resultados positivos para a primeira proposição, ou seja, um resultado positivo no incremento das vendas em função do aumento do número de linhas expostas do produto na gôndola. Para a segunda questão, os autores encontraram resultados modestos, ao passo que para a última não encontraram resultados significativos.

É assumido que os retornos marginais da elasticidade-espaço sejam decrescentes, conforme descrevem DESMET \& RENAUDIN (1998). Isto parece ser um tanto intuitivo, uma vez que o espaço ocupado por um produto dentro de um supermercado não pode crescer indefinidamente, sem prejuízo para a rentabilidade da empresa. Parece óbvio que haja um ponto em que os retornos obtidos com a maior exposição do produto sejam menos que proporcionais às perdas na lucratividade. Os motivos para essas perdas são: aumento dos custos operacionais, perda relativa aos ganhos potenciais com $\mathrm{o}$ aumento de espaço de outros produtos, e diminuição do nível de serviço logístico oferecido. Este último é decorrente da diminuição da utilidade agregada ao mix de produtos.

O estudo da elasticidade-espaço é, normalmente, complexo, na medida em que ocorrem correlações positivas e negativas, quando são considerados todos os produtos de uma loja. As elasticidades-espaço cruzadas entre os produtos, e mesmo entre categorias, caso fosse possível mensurá-las com precisão, aumentariam sobremaneira o número de variáveis exógenas no processo de modelagem matemática, além de tornar mais complexa sua utilização no dia-a-dia pelo tomador de decisão.

BROWN \& TUCKER (1961) apud CURHAN (1973) apresentam três classes de produtos, de acordo com a resposta às mudanças no espaço em que ocupam nas gôndolas. $\mathrm{Ou}$ seja, de acordo com o comportamento de suas curvas de elasticidade-espaço, podem ser classificados como:

a) produtos não-responsivos às mudanças no espaço: são geralmente aqueles que possuem elasticidade-preço de demanda inelástica, sendo o sal o exemplo clássico. Possuem uma curva de resposta praticamente constante aos incrementos no espaço nas gôndolas, conforme mostra a curva (a) da Figura 1;

b) produtos de uso geral: são aqueles em que se observa uma resposta às mudanças no espaço, mas com retornos decrescentes, conforme ilustra a curva (b) da Figura 1; e

c) produtos de consumo ocasional: suas curvas de resposta ao espaço possuem crescimento lento, até o ponto em que a quantidade do produto amostrado seja suficientemente grande para chamar a atenção do comprador (BROWN \& TUCKER, 1961 apud CURHAN, 1973). A partir deste ponto, ocorre um salto. O ponto em que serão observados retornos decrescentes aos ganhos em espaço ocupado pelo produto estará mais distante do eixo das abcissas, tendo o caso anterior como termo de comparação, como pode ser visto na curva (c) da Figura 1. Estes produtos também são conhecidos como produtos de consumo impulsivo.

DESMET \& RENAUDIN (1998), em uma estimativa das respostas à disposição espacial de diversas categorias de produtos em gôndolas, encontraram resultados que mostram que $o$ elasticidade-espaço aumenta de acordo com a taxa de consumo impulsivo de um produto, independentemente da loja amostrada (deve-se levar em conta que foram amostradas categorias de produtos de lojas de uma mesma rede).

DRÈZE et al. (1994) realizaram um estudo de caso com o objetivo de melhorar o desempenho de vendas dos produtos mudando sua posição relativa dentro da loja, bem como promovendo a alocação ótima dos produtos de acordo com as elasticidades-espaço dos produtos. Eles observaram ganhos significativos em vendas ao realocar 


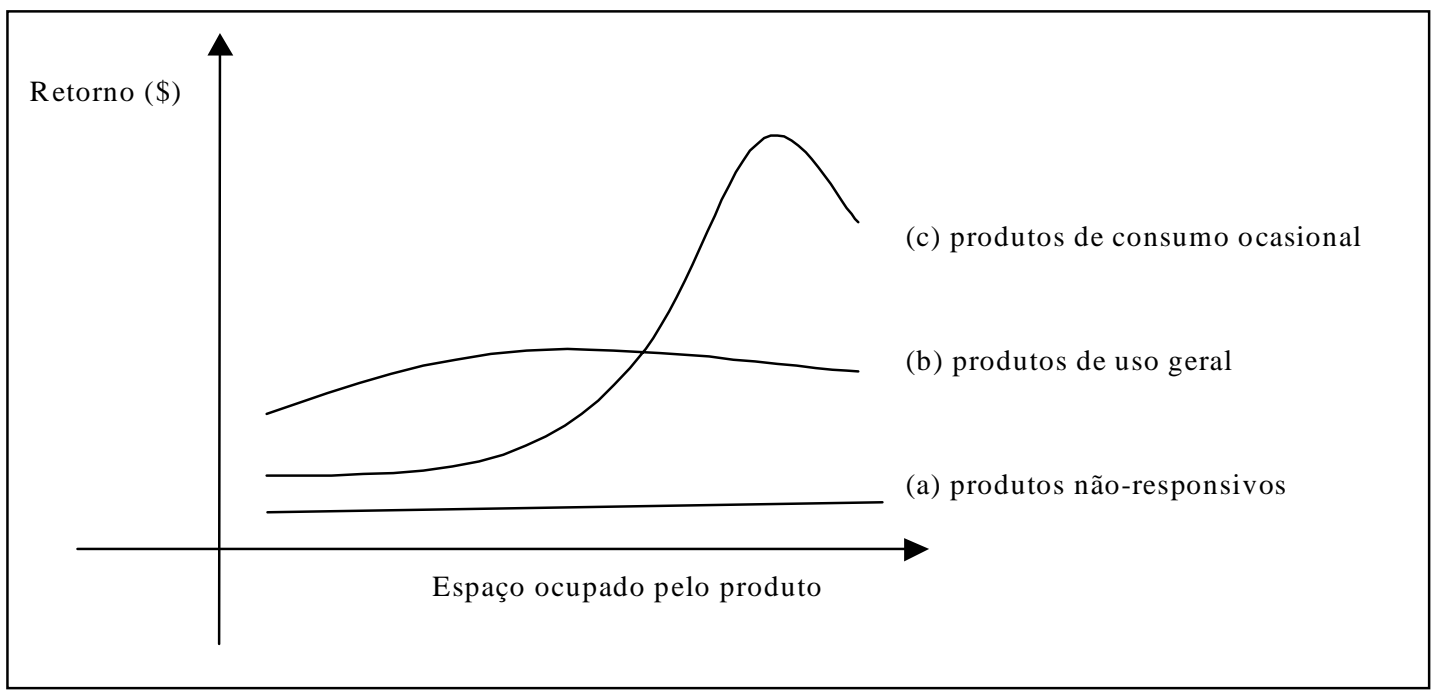

Figura 1 - Curvas de elasticidade-espaço para classes distintas de produtos.

produtos complementares, colocando-os mais próximos uns dos outros. Os ganhos médios foram de 4 a $5 \%$ dentro das categorias de produtos pesquisadas.

Esse estudo foi conduzido com produtos representativos de sete categorias de produtos, em lojas da rede de supermercados líder de mercado na cidade de Chicago. Os ganhos potenciais sobre as vendas, estimados pelos autores, foram de $15 \%$, no caso de se adotar o modelo de otimização proposto por eles, e também com o rearranjo dos produtos, utilizando dados coletados in loco. Entretanto, no mesmo estudo, é feita uma estimativa de que esses ganhos não passem de 4 a $5 \%$, em função da dinâmica do lançamento de novos produtos, e da saída de outros. Também existe o agravante de maiores custos operacionais para implementar as mudanças em todas as categorias de produtos em uma loja. Além disso, pode não haver mão-deobra suficiente para operacionalizar mudanças constantes no lay-out da loja; assim como é possível que, uma vez implementado um determinado arranjo, este esteja desatualizado, tamanha é a dinâmica do mercado de bens de consumo.

\section{O Conceito de Sortimento Eficiente}

$\mathrm{D}$ acordo com LEVY \& WEITZ (1995) apud BRONIARCZYK et al. (1998), sortimento é o número de itens diferentes em uma categoria de mercadorias.

Tanto a literatura especializada quanto os analistas e consultores do varejo alertam contra decisões no sentido de reduzir o número de itens em uma loja. A opinião geral é que podem ser obtidos ganhos no curto prazo pelo aumento de faces visíveis dos produtos com melhor desempenho de vendas. Entretanto, segundo essa idéia, no longo prazo, a percepção de sortimento dos consumidores faz com que se diminua o movimento da loja, em função da escolha dos consumidores pela loja concorrente com um melhor sortimento de produtos.

Uma prática comum no varejo é o "share-ofshelf = share-of-market", ou seja, o espaço que o tomador de decisão destina a um produto acaba sendo proporcional ao volume relativo de vendas do mesmo (BORIN \& FARRIS, 1995).

KURT SALOMON ASSOCIATES (1993) apud BRONIARCZYK et al. (1998) colocam a estratégia do "Sortimento Eficiente" como uma 
forma adotada por pequenos varejistas para obter custos operacionais menores. Existe, neste conceito, um sortimento tal que maximiza os ganhos para o varejista, uma vez que não afeta a percepção dos consumidores - em média - de um número de itens que seja o mais atrativo possível, dada uma função de custo.

BRONIARCZYK et al. (1998) tentaram desenvolver dois estudos para detectar a percepção dos consumidores em relação à redução do sortimento de itens nas gôndolas. Três questões foram levantadas nestes estudos:

a) o quanto os consumidores percebem o sortimento da loja como número de itens nas gôndolas?

b) essa percepção é orientada por razões diferentes dado o número de itens em si? e

c) a percepção de mudanças no sortimento afeta a decisão de escolha por uma loja?

Os resultados dessa pesquisa não identificaram perdas na percepção de sortimento dos consumidores quando duas condições eram satisfeitas. A primeira, quando suas marcas favoritas estavam disponíveis. A segunda, quando o espaço alocado para uma dada categoria era mantido constante. Entretanto, uma ligeira redução no número de itens provocou, ao contrário do esperado, uma preferência maior pela loja, por parte dos consumidores. Isso, desde que as marcas preferidas dos consumidores estivessem disponíveis. Este fato levou os autores a concluir que a maior facilidade com que os consumidores encontraram suas marcas preferidas possa ter ocasionado esse resultado inesperado.

Finalizando, os autores concluem que os consumidores são mais sensíveis ao espaço ocupado pelas categorias de produtos que ao espaço ocupado pelos produtos em si, no que diz respeito à questão da percepção do sortimento da loja. Esse resultado, embora não fosse de conhecimento de DESMET \& RENAUDIN (1998) por ocasião do desenvolvimento de sua pesquisa, reforçou a necessidade de um modelo de estimação da elasticidade-espaço para categorias de produtos.

Uma colocação interessante destes últimos autores diz respeito à capacidade de certos produtos gerarem tráfego na loja, e à necessidade de identificá-los para logicamente garantir-lhes um espaço privilegiado na loja. São produtos ditos "construtores de tráfego". As promoções geralmente são feitas com esse tipo de produto, mas, mesmo no caso de esses produtos não estarem em promoção, a recomendação é que tenham um espaço privilegiado, que facilite sua percepção pelo consumidor.

De acordo com BORGES (1997), a teoria comportamental é de grande valia no entendimento de como fatores do ambiente da loja têm influência no comportamento do consumidor. Respostas positivas por parte do consumidor podem ser obtidas por meio dos diversos elementos que formam a chamada atmosfera da loja.

Ainda, de acordo com o mesmo autor, sendo a função básica do lay-out facilitar a compra por parte do consumidor, é de suma importância entender o processo de associações de compras feitas pelo consumidor, ou seja, os produtos que ele considera como complementares. Assim, o autor introduz o conceito de data mining para supermercados, ou seja, a coleta e o processamento dos dados de transações dos clientes nos supermercados automatizados, buscando a verificação da existência das cestas de produtos do consumidor.

De acordo com RUSSEL \& KAMAKURA (1997), o comportamento do consumidor, em se tratando de produtos complementares e substitutos dentro da loja, pode ser monitorado por meio da análise das cestas de produtos adquiridas em cada compra feita na loja. Esses dados permitem uma modelagem do set de categorias, de acordo com as necessidades do consumidor. Também podem ser úteis na tomada de decisão quanto a um arranjo ótimo de um mix adequado de promoções de produtos. As informações assim obtidas, segundo os mesmos autores, tanto podem ser usadas nas decisões de sortimento quanto nas decisões dobre o lay-out da loja.

O estudo realizado por esses autores partiu de uma simplificação, já que eles se valeram apenas 
dos dados armazenados eletronicamente dos check-outs da rede pesquisada. Portanto, eles não discriminam quantos, e qual o relacionamento dos participantes da compra (uma só pessoa, um casal, a família toda, amigos, etc.).

O conceito de sortimento eficiente também se relaciona muito com o ambiente da loja. De acordo com DUNNE \& LUSCH (1999), os objetivos primários do ambiente de um supermercado são dois: criar a imagem da loja (ou da rede) e ampliar a produtividade do espaço de vendas da loja. O ambiente da loja, apesar de ser composto por componentes muito complexos, deve ser elaborado de tal forma que permita ao consumidor associar a imagem da rede a todas as lojas da mesma (FERNANDES, 1998). Quanto à produtividade do espaço de vendas, ela pode ser entendida por vendas totais sobre área de vendas da loja.

\section{O Modelo Empregado}

A revisão de literatura e os conceitos apresentados até então conduzem a inferências interessantes. $\mathrm{O}$ espaço alocado para os produtos tem influência direta nas vendas para produtos responsivos. Entretanto, o sortimento dos produtos deve ser conduzido de forma a, juntamente com a criação e manutenção de uma imagem favorável do supermercado, ser positivo para a decisão de escolha da loja pelo consumidor. No caso brasileiro, as pesquisas apresentadas na seção 2.6 indicam que os consumidores dão grande importância a preços e promoções, que raramente compram por impulso, e quando o fazem, o fazem por ocasião de promoções. Ora, como a resposta ao espaço alocado por produtos provavelmente deve ser um fator de menor importância, no caso brasileiro, isto faz com que o sortimento provavelmente deva ser um diferencial competitivo para os supermercados.

De acordo com NEVES (1999), as funções básicas do canal de distribuição são: a conveniência espacial, o tamanho dos lotes de produtos, o tempo de espera e a variedade de sortimento.
Considerando-se esses conceitos do ponto de vista do consumidor e o ambiente de cada loja de uma rede de supermercado (independente dos formatos), como canal de distribuição final para ele, podem-se inferir considerações interessantes. Por um lado, a correta distribuição espacial por categorias e a maior alocação de espaço para produtos com melhor resposta às vendas melhoram a conveniência espacial para $\mathrm{o}$ consumidor. Por outro lado, essa alocação ótima de espaço pode afetar o sortimento adequado de produtos, ou seja, o serviço representado pela variedade de sortimentos.

BRONIARCZYK et al. (1998) observaram em seu estudo, como citado anteriormente, que os consumidores são mais sensíveis ao espaço ocupado pelas categorias de produtos que ao espaço ocupado pelos produtos em si, no que diz respeito à questão da percepção do sortimento da loja.

Será, então, verificada a existência, ou não, da correlação entre o tamanho das lojas e o tamanho de suas seções. Não será usado critério de categorias, mas sim a divisão por seções, uma simplificação que apenas vai auxiliar na pesquisa. Também não foi considerado como necessário o conhecimento do critério de divisão da rede de supermercados para efeitos da pesquisa. Caso não haja correlação entre o tamanho de cada seção tomada uma a uma e o tamanho da loja, pode haver uma estratégia da rede de supermercados de atendimento mais localizado da demanda, para determinado formato em relação aos outros. A comparação entre os resultados dos diferentes formatos, e entre os mesmos tomados dois a dois, pode ajudar a elucidar a estratégia da rede para cada formato.

De acordo com BRONIARCZYK et al. (1998), categorias que não variem de tamanho (ao menos para lojas de mesmo formato), mas que tenham as marcas preferidas dos consumidores, não têm necessariamente que ter um maior número de itens para passar a idéia de sortimento para o consumidor, em relação a outras lojas (ao menos de mesmo formato). Ora, tendo isso em vista, o tamanho da seção pode ser percebido pelo 
consumidor como sendo o parâmetro mais forte de sortimento daquela seção dentro de uma loja.

A rede pesquisada possui grande poder de negociação com seus fornecedores, dada sua posição entre as líderes de mercado. Seu centro de distribuição próximo à Capital e o fato de adotar as práticas do ECR sinalizam para a pressuposição de que as marcas líderes de cada categoria estão sempre presentes nas lojas.

De forma consciente ou não, a rede pode ter um sortimento uniforme de suas seções (aqui medido pelo proxy de seu tamanho), independentemente do formato, ou mesmo do tamanho (nesse caso se torna mais interessante a observação dentro de um mesmo formato).

Assim sendo, proceder-se-á ao seguinte teste de hipóteses:

$\mathrm{H}_{0 \mathrm{i}}$ : A correlação entre a área das lojas (em metros quadrados) e o tamanho das faces visíveis dos produtos da i-ésima seção é zero.

$\mathrm{H}_{0 \mathrm{ij}}$ : A correlação entre a área das lojas de formato $\mathrm{j}$ (em metros quadrados) e o tamanho das faces visíveis dos produtos da i-ésima seção é zero.

Será realizado também o teste entre lojas de formatos diferentes, tomadas duas a duas, exceto para o caso compacto/grande para se evitar o risco de se estar comparando duas populações diferentes, em função da perda de continuidade na amostra.

Para efeitos de testes de hipóteses, será utilizado o teste estatístico $t$ de Student para testar o coeficiente de correlação de Pearson entre a área da lojas, em metros quadrados, e o tamanho de cada seção.

Tem-se então:

$$
\begin{aligned}
& r=\frac{\sum_{i=1}^{n} x_{i} y_{i}}{\sqrt{\sum_{i=1}^{n} x_{i}^{2} \sum_{i=1}^{n} y_{i}^{2}}} \\
& t=\frac{r \sqrt{n-2}}{\sqrt{1-r^{2}}}
\end{aligned}
$$

onde:

$\mathrm{x}_{\mathrm{i}} \quad$ é a diferença entre a média de tamanho das lojas e o tamanho da loja i;

$\mathrm{y}_{\mathrm{i}}$ é a diferença entre a média dos tamanhos da seções nas lojas e o tamanho da seção na loja i;

$r$ é o coeficiente de correlação de Pearson;

t é a estatística $t$ de Student para o teste de hipóteses; e

n é o número de observações.

Será testada a hipótese com nível de significância de $5 \%$, com os valores de $t$ em módulo. Dado que não se conhece a estratégia adotada pela rede de supermercados pesquisada, não se pode inferir que o tamanho da loja seja direta ou indiretamente proporcional ao tamanho das seções. Portanto, será aplicado um teste $t$ de Student bidirecional.

\section{Especificação dos Dados}

$\mathrm{O}$ estudo de caso realizado para este trabalho foi conduzido em dezoito lojas de uma rede de supermercados, na cidade de São Paulo, no período compreendido entre a última semana de outubro e a primeira semana do mês de dezembro de 2000.

A área útil das lojas, para fins de classificação quanto ao formato, foi considerada como sendo aquela compreendida entre o final da área de vendas da loja, mesmo que esteja tomada por um balcão frigorífico ou outro equipamento qualquer, até o início dos check-outs da loja. Em outras palavras, trata-se da área disponível para vendas da loja, excluindo-se assim as áreas de estacionamento, administração, estoque, entre outras, conforme o descrito por BRITO (1998).

O lay-out das lojas é o de $4^{\mathrm{a}}$ geração, considerado como uma evolução da $3^{\mathbf{a}}$ geração, possuindo áreas privilegiadas para a seção de frutas, legumes e verduras, ou FLV. A $4^{\text {a }}$ geração difere da anterior por incorporar as seções de flores e peixaria, e ter áreas para pratos prontos e congelados maiores, sendo a padaria seu principal gerador de tráfego. 
Tabela 1 - Equivalência de unidades usadas na pesquisa e unidades do SI.

\begin{tabular}{cc}
\hline Medida em passos & Medida em metros \\
\hline 1 passo & $0,89 \mathrm{~m}$ \\
1 passo quadrado (área) & $0,7921 \mathrm{~m}^{2}$ \\
\hline
\end{tabular}

Tabela 2 - Dados levantados para o trabalho, por meio de pesquisa de campo.

\begin{tabular}{cc}
\hline Dado & Forma de obtenção \\
\hline Tamanho da loja & $\begin{array}{c}\text { Contagem de passos entre as extremidades da } \\
\text { área útil da loja. }\end{array}$ \\
Tamanho da seção & Medição e contagem dos módulos das \\
gôndolas. \\
Formato da loja & $\begin{array}{c}\text { Verificação direta na loja pesquisada, através } \\
\text { do roteiro descrito por BRITO (1998). }\end{array}$ \\
\hline
\end{tabular}

Exemplos dos lay-outs das lojas amostradas são apresentados no Anexo 1.

O método utilizado para medir a área das lojas amostradas foi o da contagem de passos entre as suas extremidades. Este método é mais preciso do que inicialmente possa parecer. Foi tomado o cuidado de se usar o mesmo sapato de solado baixo em todas as visitas nas lojas. As medições sempre conferiam quando se procedia à repetição da contagem dos passos. Outro fator primordial para encorajar esse processo foi o fato de que um passo do pesquisador sempre tinha a mesma medida: oitenta e nove centímetros. A conversão utilizada está ilustrada na Tabela 1 .

Já a medição das faces visíveis dos produtos nas gôndolas foi possível graças a uma constatação feita anteriormente durante visitas em várias lojas da rede de supermercados pesquisada: as gôndolas são formadas por módulos que possuem poucos padrões de tamanho, que se repetem não só dentro da mesma loja, mas em várias lojas da rede. A simples medição de alguns destes módulos já era o suficiente. Bastava então a contagem de quantos módulos cada seção dispunha em cada loja. Esses módulos variavam de tamanho, desde cinqüenta centímetros até um metro e trinta, sendo esta última a medida do módulo mais utilizado nas lojas amostradas. Em alguns casos, foi necessário medir módulos adaptados, usados em locais junto a colunas, por exemplo.

A classificação das seções da loja foi normatizada de acordo com a especificação ilustrada no website pertencente ao mesmo grupo da rede de supermercado pesquisada. É uma classificação que cabe apenas à rede pesquisada, mas muito útil para fins de normatização nesta pesquisa. Para fins deste trabalho, foram levantadas apenas as seguintes seções: bonbonnière, dietéticos, enlatados, mercearia, produtos de limpeza e pet shop.

A Tabela 2 ilustra os dados levantados para o trabalho por meio da pesquisa de campo, relacionando o tipo de dado necessário com sua respectiva forma de obtenção.

Já a Tabela 3 ilustra os resultados esperados a partir da aplicação dos modelos, indicando os procedimentos a serem tomados de acordo com o teste de hipóteses proposto.

Cabe ressaltar, para um perfeito entendimento do trabalho, que não foi feita qualquer distinção entre marcas de produtos, tendo sido apenas identificadas as seções dentro das lojas conforme o tipo de produto que possuíam. 
Tabela 3 - Resultados esperados a partir da aplicação dos modelos.

\begin{tabular}{ll}
\hline \multicolumn{1}{c}{ Variável endógena } & \multicolumn{1}{c}{ Objetivo/Hipótese } \\
\hline $\begin{array}{l}\text { Coeficiente de correlação de } \\
\text { Pearson } r \text { entre o tamanho da } \\
\text { loja e o tamanho da seção. } \\
\text { Para todas as lojas. }\end{array}$ & $\begin{array}{l}\text { Se o teste } t \text { de Student for significativo no nível de 5\%, então não se rejeita a } \\
\text { hipótese nula de que haja correlação direta entre o tamanho da loja e o } \\
\text { tamanho da seção, independentemente do formato da loja. }\end{array}$ \\
$\begin{array}{l}\text { Coeficiente de correlação de } \\
\text { Pearson } r \text { entre o tamanho da } \\
\text { loja e o tamanho da seção. }\end{array}$ & $\begin{array}{l}\text { Se o teste } t \text { de Student for significativo no nível de 5\%, então não se rejeita a } \\
\text { hipótese nula de que haja correlação direta entre o tamanho da loja e o } \\
\text { tamanho da seção, para cada formato de loja. }\end{array}$ \\
$\begin{array}{l}\text { Para cada formato de loja. } \\
\text { Pearson } r \text { entre o tamanho da } \\
\text { loja e o tamanho da seção. } \\
\text { Para os formatos tomados } \\
\text { dois a dois, exceto compacto/ } \\
\text { grande }{ }^{1} .\end{array}$ & $\begin{array}{l}\text { Se o teste } t \text { de Student for significativo no nível de 5\%, então não se rejeita a } \\
\text { tamanho da seção. para os formatos de loja tomados dois a dois. }\end{array}$ \\
\hline
\end{tabular}

${ }^{1}$ A quebra de continuidade de formatos induziria a uma comparação entre duas populações.

A seção de enlatados não pôde ser claramente separada por módulos definidos da seção de mercearia. Portanto, mercearia e enlatados foram tratados como sendo uma única seção.

\section{Resultados}

$\mathrm{D}$ as dezoito lojas visitadas, duas foram excluídas como outliers, devido ao seu layout irregular que dificultava sua comparação com as demais.

Os resultados intermediários, obtidos a partir da aplicação dos modelos para a seção bonbonnière, são ilustrados na Tabela 4.

De acordo com o Quadro 1, para a seção de bonbonnière foi rejeitada a hipótese nula, quando são considerados todos os formatos de loja. Porém ela não é rejeitada quando se tomam as amostragens de formato em particular. Deve ser feita uma ressalva em relação aos formatos compacto e grande, que apresentam apenas dois graus de liberdade, devido à sua baixa ocorrência na amostragem geral. Já para o formato convencional, dão-se como satisfatórios 6 graus de liberdade para não rejeitar a hipótese nula.
Quando se consideram as amostragens das lojas compactas/convencionais e convencionais/ grandes, rejeita-se a hipótese nula de correlação zero entre tamanho das lojas e tamanho da seção de bonbonnière.

Os resultados intermediários, obtidos a partir da aplicação dos modelos para a seção diet, estão ilustrados na Tabela 5.

Já no Quadro 2 estão ilustrados os resultados análogos para a seção diet. Portanto, rejeita-se a hipótese nula para a amostragem de todas as lojas em conjunto, e para os conjuntos compacto/ convencional e convencional/grande. Não se rejeita a hipótese nula para o caso de cada formato em particular.

Os resultados intermediários, obtidos a partir da aplicação dos modelos para a seção material de limpeza, são ilustrados na Tabela 6 .

Para a seção de material de limpeza, conforme ilustrado na Quadro 3, obtiveram-se valores negativos de correlação nos formatos compacto e convencional, e para o conjunto compacto/ convencional. Não se rejeita a hipótese nula para cada formato individual e também para o conjunto compacto/convencional. A hipótese nula é rejeitada nos demais casos. 
Tabela 4 - Resultados intermediários para a seção bonbonnière a partir da aplicação dos modelos.

\begin{tabular}{lccc}
\hline \multicolumn{1}{c}{ Formato das lojas } & $\begin{array}{c}\text { Coeficiente de correlação de } \\
\text { Pearson } r \text { entre o tamanho da } \\
\text { loja e o tamanho da seção. }\end{array}$ & $\begin{array}{c}\text { Valor do teste } t \text { de } \\
\text { Student }\end{array}$ & $\begin{array}{c}\text { Valor crítico de } t \text {, ao } \\
\text { nível de significância } \\
\text { de 5\% }\end{array}$ \\
\hline Para todas as lojas & 0,852 & 6,092 & 2,145 \\
compacto & 0,884 & 2,674 & 4,303 \\
convencional & 0,418 & 1,126 & 2,447 \\
grande & 0,624 & 1,129 & 4,303 \\
compacto e convencional & 0,701 & 3,107 & 2,228 \\
convencional e grande & 0,808 & 4,344 & 2,228 \\
\hline
\end{tabular}

Quadro 1 - Resultados de correlação e testes de hipóteses para a seção de bonbonnière.

\begin{tabular}{|cl|cl|}
\hline compacto & & todos os formatos & valor \\
$r$ & 0,884 & $r$ & 0,852 \\
$t$ & 2,674 & $t$ & 6,092 \\
Valor de $t$ crítico & 4,303 & Valor de $t$ crítico & 2,145 \\
G.L. & 2 & G.L. & 14 \\
& não rejeitada & & rejeitada \\
& & & \\
convencional & & compacto e convencional & \\
$r$ & 0,418 & $r$ & 0,701 \\
$t$ & 1,126 & $t$ & 3,107 \\
Valor de $t$ crítico & 2,447 & Valor de $t$ crítico & 2,228 \\
G.L. & 6 & G.L. & 10 \\
& não rejeitada & & rejeitada \\
& & convencional e grande & \\
grande & & $r$ & 0,808 \\
$r$ & 0,624 & $t$ & 4,344 \\
$t$ & 1,129 & Valor de $t$ crítico & 2,228 \\
Valor de $t$ crítico & 4,303 & G.L. & 10 \\
G.L. & 2 & & rejeitada \\
& não rejeitada & &
\end{tabular}

Os resultados intermediários, obtidos a partir da aplicação dos modelos para a seção de enlatados e mercearia, estão ilustrados na Tabela 7.

A seção composta pelas seções de enlatados e mercearia, curiosamente, apresentou não só resultados similares aos da seção de limpeza para os testes de hipóteses como também apresentou valores negativos de correlação nas mesmas amostragens: formatos compacto e convencional e no conjunto compacto/convencional (vide Quadro 4). Esse fato pode ser um indicativo de uma provável estratégia da rede para as seções de menor valor agregado (Quadro 4). 
Tabela 5 - Resultados intermediários para a seção diet a partir da aplicação dos modelos.

\begin{tabular}{lccc}
\hline Formato das lojas & $\begin{array}{c}\text { Coeficiente de correlação de } \\
\text { Pearson } r \text { entre o tamanho da } \\
\text { loja e o tamanho da seção. }\end{array}$ & $\begin{array}{c}\text { Valor do teste } t \text { de } \\
\text { Student }\end{array}$ & $\begin{array}{c}\text { Valor crítico de } t \text {, ao } \\
\text { nível de significância } \\
\text { de 5\% }\end{array}$ \\
\hline Para todas as lojas & 0,737 & 4,078 & 2,145 \\
compacto & 0,650 & 1,209 & 4,303 \\
convencional & 0,441 & 1,204 & 2,447 \\
grande & 0,403 & 0,622 & 4,303 \\
compacto e convencional & 0,720 & 3,277 & 2,228 \\
convencional e grande & 0,693 & 3,040 & 2,228 \\
\hline
\end{tabular}

Quadro 2 - Resultados de correlação e testes de hipóteses para a seção diet.

\begin{tabular}{|c|c|c|c|}
\hline compacto & & todos os formatos & valor \\
\hline$r$ & 0,650 & $r$ & 0,737 \\
\hline$t$ & 1,209 & $t$ & 4,078 \\
\hline Valor de $t$ crítico & 4,303 & Valor de $t$ crítico & 2,145 \\
\hline G.L. & $\begin{array}{l}2 \\
\text { não rejeitada }\end{array}$ & G.L. & $\begin{array}{l}14 \\
\text { rejeitada }\end{array}$ \\
\hline convencional & & compacto e convencional & \\
\hline$r$ & 0,441 & $r$ & 0,720 \\
\hline$t$ & 1,204 & $t$ & 3,277 \\
\hline Valor de $t$ crítico & 2,447 & Valor de $t$ crítico & 2,228 \\
\hline G.L. & $\begin{array}{l}6 \\
\text { não rejeitada }\end{array}$ & G.L. & $\begin{array}{l}10 \\
\text { rejeitada }\end{array}$ \\
\hline grande & & convencional e grande & \\
\hline$r$ & 0,403 & $r$ & 0,693 \\
\hline$t$ & 0,622 & $t$ & 3,040 \\
\hline Valor de $t$ crítico & 4,303 & Valor de $t$ crítico & 2,228 \\
\hline G.L. & $\begin{array}{l}2 \\
\text { não rejeitada }\end{array}$ & G.L. & $\begin{array}{l}10 \\
\text { rejeitada }\end{array}$ \\
\hline
\end{tabular}

Os resultados intermediários, obtidos a partir da aplicação dos modelos para a seção pet, estão ilustrados na Tabela 8.

Finalizando com a seção pet, que é uma seção dedicada aos animais domésticos, esta também apresentou resultados semelhantes aos encontrados nas duas seções anteriores para os testes de hipóteses. Ela apresentou valores negativos de correlação apenas para o formato convencional e para o conjunto compacto/convencional (vide Quadro 5).

Embora os formatos compacto e grande tenham sido composto de apenas quatro lojas 
Tabela 6 - Resultados intermediários para a seção material de limpeza a partir da aplicação dos modelos.

\begin{tabular}{lccc}
\hline \multicolumn{1}{c}{ Formato das lojas } & $\begin{array}{c}\text { Coeficiente de correlação de } \\
\text { Pearson } r \text { entre o tamanho da } \\
\text { loja e o tamanho da seção }\end{array}$ & $\begin{array}{c}\text { Valor do teste } t \text { de } \\
\text { Student }\end{array}$ & $\begin{array}{c}\text { Valor crítico de } t \text {, ao } \\
\text { nível de significância } \\
\text { de 5\% }\end{array}$ \\
\hline Para todas as lojas & 0,731 & 4,007 & 2,145 \\
compacto & $-0,123$ & $-0,175$ & 4,303 \\
convencional & $-0,410$ & $-1,100$ & 2,447 \\
grande & 0,792 & 1,834 & 4,303 \\
compacto e convencional & $-0,129$ & $-0,410$ & 2,228 \\
convencional e grande & 0,705 & 3,145 & 2,228 \\
\hline
\end{tabular}

Quadro 3 - Resultados de correlação e testes de hipóteses para a seção de material de limpeza.

\begin{tabular}{|c|c|c|c|}
\hline compacto & & todos os formatos & valor \\
\hline$r$ & $-0,123$ & $r$ & 0,731 \\
\hline$t$ & $-0,175$ & $t$ & 4,007 \\
\hline Valor de $t$ crítico & 4,303 & Valor de $t$ crítico & 2,145 \\
\hline G.L. & $\begin{array}{l}2 \\
\text { não rejeitada }\end{array}$ & G.L. & $\begin{array}{l}14 \\
\text { rejeitada }\end{array}$ \\
\hline convencional & & compacto e convencional & \\
\hline$r$ & $-0,410$ & $r$ & $-0,129$ \\
\hline$t$ & $-1,100$ & $t$ & $-0,410$ \\
\hline Valor de $t$ crítico & 2,447 & Valor de $t$ crítico & 2,228 \\
\hline G.L. & $\begin{array}{l}6 \\
\text { não rejeitada }\end{array}$ & G.L. & $\begin{array}{l}10 \\
\text { não rejeitada }\end{array}$ \\
\hline grande & & convencional e grande & \\
\hline$r$ & 0,792 & $r$ & 0,705 \\
\hline$t$ & 1,834 & $t$ & 3,145 \\
\hline Valor de $t$ crítico & 4,303 & Valor de $t$ crítico & 2,228 \\
\hline G.L. & $\begin{array}{l}2 \\
\text { não rejeitada }\end{array}$ & G.L. & $\begin{array}{l}10 \\
\text { rejeitada }\end{array}$ \\
\hline
\end{tabular}

pesquisadas, em nenhuma das seções se rejeitou a hipótese nula, e os dados, em todas as diferenças entre os tamanhos, indicam para a sua não-rejeição, mesmo tendo apenas dois graus de liberdade. Já para o formato convencional, provavelmente o mais comum entre as lojas da rede, pode-se ter uma maior segurança quanto à não-rejeição da hipótese nula, no nível de 5\%.

A hipótese nula foi rejeitada em todos os casos em que as lojas foram tomadas em conjunto. Para o nível de significância de 5\%, rejeitou-se a hipótese de que não haja correlação 
Tabela 7 - Resultados intermediários para a seção enlatados e mercearia a partir da aplicação dos modelos.

\begin{tabular}{lccc}
\hline \multicolumn{1}{c}{ Formato das lojas } & $\begin{array}{c}\text { Coeficiente de correlação de } \\
\text { Pearson } r \text { entre o tamanho da } \\
\text { loja e o tamanho da seção }\end{array}$ & $\begin{array}{c}\text { Valor do teste } t \text { de } \\
\text { Student }\end{array}$ & $\begin{array}{c}\text { Valor crítico de } t \text {, ao } \\
\text { nível de significância } \\
\text { de 5\% }\end{array}$ \\
\hline Para todas as lojas & 0,793 & 4,869 & 2,145 \\
compacto & $-0,428$ & $-0,669$ & 4,303 \\
convencional & $-0,193$ & $-0,481$ & 2,447 \\
grande & 0,321 & 0,479 & 4,303 \\
compacto e convencional & $-0,115$ & $-0,366$ & 2,228 \\
convencional e grande & 0,796 & 4,162 & 2,228 \\
\hline
\end{tabular}

Quadro 4 - Resultados de correlação e testes de hipóteses para a seção de mercearia e enlatados.

\begin{tabular}{|cl|cl|}
\hline compacto & & todos os formatos & valor \\
$r$ & $-0,428$ & $r$ & 0,793 \\
$t$ & $-0,669$ & $t$ & 4,869 \\
Valor de $t$ crítico & 4,303 & Valor de $t$ crítico & 2,145 \\
G.L. & 2 & G.L. & 14 \\
& não rejeitada & & rejeitada \\
& & & \\
convencional & & compacto e convencional & \\
$r$ & $-0,193$ & $r$ & $-0,115$ \\
$t$ & $-0,481$ & $t$ & $-0,366$ \\
Valor de $t$ crítico & 2,447 & Valor de $t$ crítico & 2,228 \\
G.L. & 6 & G.L. & 10 \\
& não rejeitada & & não rejeitada \\
& & convencional e grande & \\
grande & & $r$ & 0,796 \\
$r$ & 0,321 & $t$ & 4,162 \\
$t$ & 0,479 & Valor de $t$ crítico & 2,228 \\
Valor de $t$ crítico & 4,303 & G.L. & 10 \\
G.L. & 2 & & rejeitada \\
& não rejeitada & &
\end{tabular}

entre o tamanho do supermercado e o tamanho das seções, desconsiderando-se o formato da loja.

Consultores especializados no varejo afirmam existir uma tendência crescente no mercado varejista a partir de meados da década de noventa: lojas de formatos compacto e convencional bem localizadas, com características personalizadas de serviços, sortimento de produtos e lay-out seriam as soluções mais competitivas no mercado. O conhecimento das características mais valorizadas pela população 
Tabela 8 - Resultados intermediários para a seção pet a partir da aplicação dos modelos.

\begin{tabular}{lccc}
\hline \multicolumn{1}{c}{ Formato das lojas } & $\begin{array}{c}\text { Coeficiente de correlação de } \\
\text { Pearson } r \text { entre o tamanho da } \\
\text { loja e o tamanho da seção. }\end{array}$ & $\begin{array}{c}\text { Valor do teste } t \text { de } \\
\text { Student }\end{array}$ & $\begin{array}{c}\text { Valor crítico de } t \text {, ao } \\
\text { nível de significância } \\
\text { de 5\% }\end{array}$ \\
\hline Para todas as lojas & 0,807 & 5,108 & 2,145 \\
compacto & 0,474 & 0,762 & 4,303 \\
convencional & $-0,306$ & $-0,786$ & 2,447 \\
grande & 0,749 & 1,600 & 4,303 \\
compacto e convencional & $-0,307$ & $-1,020$ & 2,228 \\
convencional e grande & 0,877 & 5,777 & 2,228 \\
\hline
\end{tabular}

Quadro 5 - Resultados de correlação e testes de hipóteses para a seção pet.

\begin{tabular}{|cl|cl|}
\hline compacto & & todos os formatos & valor \\
$r$ & 0,474 & $r$ & 0,807 \\
$t$ & 0,762 & $t$ & 5,108 \\
Valor de $t$ crítico & 4,303 & Valor de $t$ crítico & 2,145 \\
G.L. & 2 & G.L. & 14 \\
& não rejeitada & & rejeitada \\
& & & \\
convencional & & compacto e convencional & \\
$r$ & $-0,306$ & $r$ & $-0,307$ \\
$t$ & $-0,786$ & $t$ & $-1,020$ \\
Valor de $t$ crítico & 2,447 & Valor de $t$ crítico & 2,228 \\
G.L. & 6 & G.L. & 10 \\
& não rejeitada & & não rejeitada \\
grande & & convencional e grande & \\
$r$ & 0,749 & $r$ & 0,877 \\
$t$ & 1,600 & $t$ & 5,777 \\
Valor de $t$ crítico & 4,303 & Valor de $t$ crítico & 2,228 \\
G.L. & 2 & G.L. & 10 \\
& não rejeitada & & rejeitada \\
\hline
\end{tabular}

local e seu nível de satisfação com as alternativas disponíveis - tanto próprias quanto dos concorrentes - seriam as grandes vantagens competitivas neste mercado (LOJA certa no..., 1999).

Os resultados aqui encontrados sugerem uma certa diferença no tamanho de seções dos supermercados compactos e convencionais em relação aos de formato grande, nas seções de material de limpeza, pet, mercearia e enlatados. Essa especulação pode ser reforçada por trabalhos de cunho mais específico, para confirmar ou não uma diferença de estratégia, dado o formato da loja. 


\section{Considerações Finais}

Drovavelmente, as lojas de formato compacto e convencional sejam desenhadas para atender uma demanda ainda mais localizada que as lojas de formato grande. Essa constatação se deve aos resultados encontrados nas seções de material de limpeza, mercearia e enlatados e pet.

O fato de não se rejeitar sistematicamente a hipótese nula de que a correlação entre $o$ tamanho da loja e o tamanho da seção seja zero, para todas as seções nos três formatos de loja, é um forte indicador de que as decisões gerenciais, no tocante à alocação de espaço nas gôndolas de lojas da rede, sejam muito mais localizadas do que poderia se esperar em uma rede, principalmente, quando se trata de uma rede cuja maioria dos produtos são originados a partir de um centro de distribuição.

Outro fato interessante é que a estratégia da rede em si pode ser realmente voltada para os consumidores dos arredores das lojas, servindo mesmo como um supermercado de bairro, apesar da maioria das lojas possuir amplo estacionamento.

Os produtos das seções de mercearia e enlatados, e de material de limpeza chegaram a apresentar uma correlação negativa entre tamanho da loja e tamanho da seção. Embora tenha sido rejeitada a hipótese nula, vale a constatação de que esses produtos tenham uma estratégia diferente em relação aos demais. Quanto à seção pet, um fato curioso é que no conjunto de lojas compacto/convencional, os valores encontrados de tamanho praticamente não variaram tanto quanto nas outras seções.
Isso pode indicar um provável tamanho limite para essa seção nas lojas.

O número de lojas amostradas nos formatos compacto e grande foi um tanto pequeno, o que compromete a confiabilidade dos resultados obtidos para os mesmos. Nesse sentido, novos trabalhos, para cada tipo de formato, devem ser realizados a fim de validar os resultados encontrados nesse trabalho para esses dois formatos.

$\mathrm{O}$ fato de não se ter rejeitado a hipótese nula em nenhuma seção para os dois formatos e de o formato convencional também não ter apresentado rejeição da hipótese nula sinaliza para uma provável confirmação dos resultados aqui encontrados para amostras maiores.

Quanto à imagem da rede, provavelmente o sortimento não pode ser considerado um fator gerador da imagem da rede, pelo menos no aspecto quantitativo. Sem dúvida, o espaço físico de cada loja em particular pode ser um fator limitante para uma maior padronização do tamanho das seções.

Alguns produtos pertencentes às seções amostradas também se encontravam em locais estratégicos da loja e fora das gôndolas, mas não foram levados em conta na amostragem, não só pela dificuldade de medição, mas também pelo fato de ser muito alta a rotatividade dos produtos nestes pontos.

Uma limitação a ser destacada é o fato de que nem todas as seções puderam ser amostradas, ou por não usarem gôndolas, ou pelo fato de as gôndolas serem alocadas de tal forma que se tornava difícil ou quase impossível sua medição. Nesse sentido, estudos sobre o comportamento do consumidor para cada seção específica devem continuar a ser incentivados. 
Anexo 1 - Lay-out das lojas amostradas, de acordo com o formato.

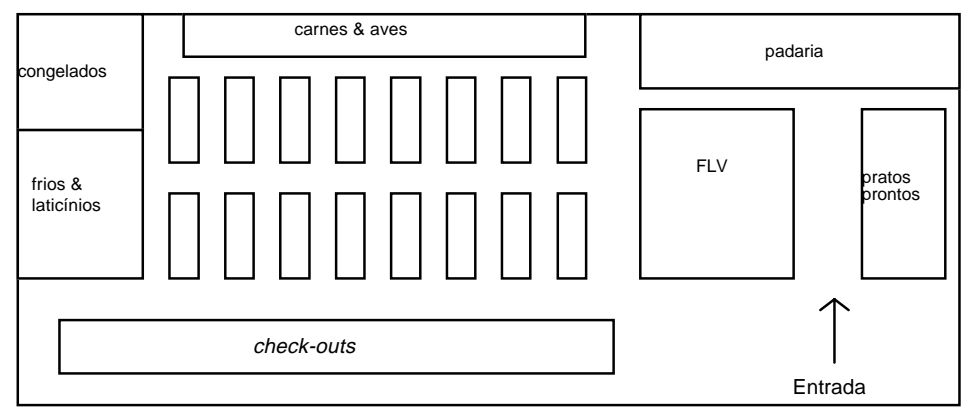

Figura A - Exemplo de loja de formato compacto.

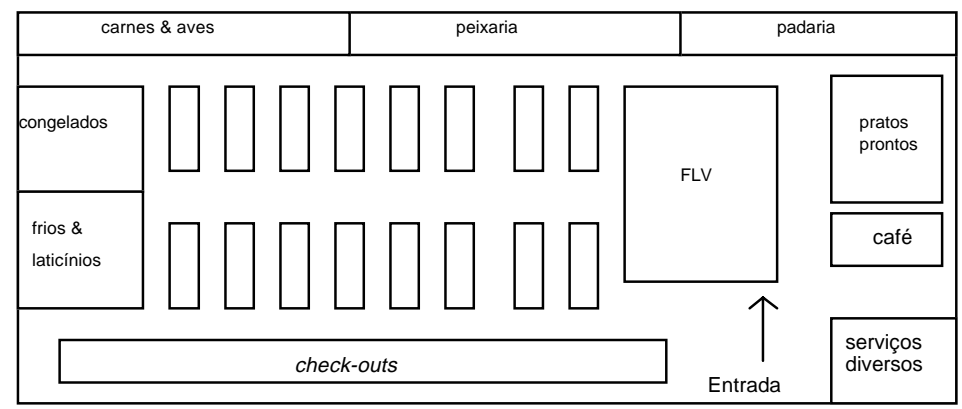

Figura B - Exemplo de loja de formato convencional.

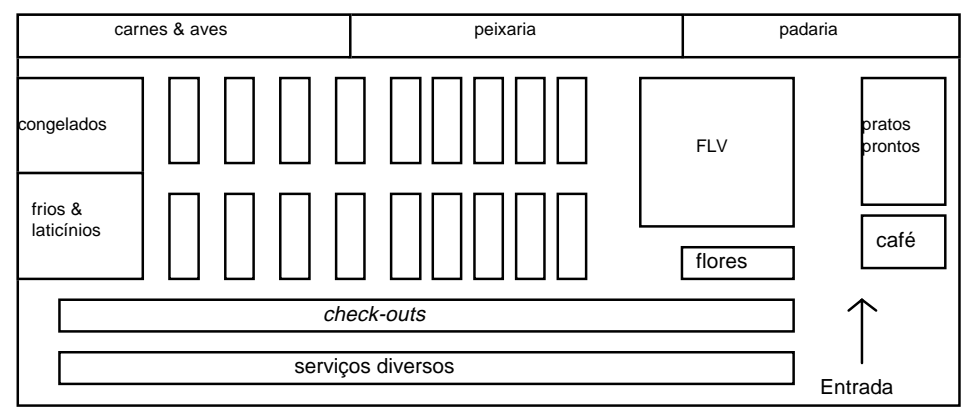

Figura C - Exemplo de loja de formato grande.

\section{Referências Bibliográficas}

BORGES JR, A.A. Lay-out e disposição de produtos no varejo: a influência da teoria comportamental. In: DE ANGELO, C.F.; DA SILVEIRA, J.A.G. Varejo competitivo. Programa de Administração de Varejo. São Paulo: Atlas, 1997. v.2, cap.12, p.238-51.
BORIN, N.; FARRIS, P. A sensitivy analysis of retailer shelf management models. Journal of Retailing, v.71, n.2, p.153-71, May 1995.

BRITO, D. Qual é o formato correto de sua loja. SuperHiper, v.24, p.74-7, set. 1998. 
BRONIARCZYK, S.M.; HOYER, W.D.; McALISTER, L. Consumers' perceptions of the assortement offered in a grocery category: The impact of item reduction. Journal of Marketing Research, v.35, p.166-76, May 1998.

CURHAN, R.C. The relationship between shelf space and unit sales in supermarkets. Journal of Marketing Research, v.9, p.406-12, Nov. 1972.

CURHAN, R.C. Shelf space allocation and profit maximization in mass retailing. Journal of Marketing, v.37, n.3, p.54-60, July 1973.

DESMET, P.; RENAUDIN, V. Estimation of product category sales responsiveness to allocated shelf space. International Journal of Research in Marketing, v.15, p.443-457, 1998.

DRÈZE, X.; HOCH, S.J.; PURK, M.E. Shelf management and space elasticity. Journal of Retailing, v.70, n.4, p.301-26, 1994.

DUNNE, P.; LUSCH, R.F. Retailing. Fort Worth: The Dryden Press, 1999. 621p.

FERNANDES, S. Comunicação visual em supermercados e hipermercados em São Paulo: um estudo de caso. São Paulo, 1998. 220p. Dissertação (mestrado) - Escola de Comunicação e Artes, Universidade de São Paulo.
FRANK, R.E.; MASSY, W.F. Shelf position and space effects on sales. Journal of Marketing Research, v.7, n.1, p.59-66, Feb. 1970.

LOJA certa no ponto certo. SuperHiper, v.25, n.289, p.76-7, set. 1999.

NEVES, M.F. Um Modelo para Planejamento de Canais de Distribuição no Setor de Alimentos. São Paulo, 1999. 297p. Tese (doutorado) Faculdade de Economia, Administração e Contabilidade, Universidade de São Paulo.

RUSSEL, G.J.; KAMAKURA, W.A. Modeling multiple category brand preference with household basket data. Journal of Retailing, v.73, n.4, p.439-61, 1997.

TENDÊNCIAS de lay-out atedem perfil do cliente. SuperHiper, v.25, n.287, p.18-30, jul. 1999.

YANG, M.H.; CHEN, W.C. A study on shelf space allocation and management. International Journal of Production Economics, v.60-61, p.309-317, Apr. 1999.

\title{
ALLOCATION OF PRODUCTS ON SUPERMARKET'S SHELVES: A CASE STUDY
}

\begin{abstract}
This study was done with the objective of verifying the possible existence of a pattern of distribution of the products on the supermarket's shelves, considering the size and format of the stores. A case study was conducted in stores of a great chain in the city of São Paulo, where the relationship between the space allocation decisions and the size and the format of the stores were evaluated. It was expected that the bigger the correlation of the space allocated to sections and the size of the stores, the clearer the pattern of the chain; or, if this correlation does not exist, the chain could be more focused on the neighborhood's demand. For this study, three supermarket formats were considered: compact, normal and large. The obtained results suggest that stores with the compact and normal format are more related to attend neighborhood demands than the stores with the large format. The fact that the null hypothesis - the size of the stores and the size of the sections have zero correlation - was systematically not rejected for the three store formats is a strong signal that the managerial decisions about shelf space allocation to stores of this chain could be more associated to the neighborhood than it would be expected from a chain. One reason for that is the fact that this chain has a very representative part of its products originated from its distribution center.
\end{abstract}

Key words: shelves, space-elasticity, efficient assortment, supermarket. 